\title{
Do overtourism à estagnação. Reflexões sobre a pandemia do Coronavírus e o turismo
}

\author{
Del overtourism al estancamiento. Reflexiones sobre la pandemia de coronavirus y el \\ turismo
}

\author{
From overtourism to stagnation. Reflections on the Coronavirus pandemic and the \\ tourism
}

\author{
Alexandre Panosso Netto ${ }^{1}$ \\ J. Laize Soares Oliveira ${ }^{2}$ \\ Valéria Ferraz Severini ${ }^{3}$
}

\begin{abstract}
Resumo: O presente texto originou-se do convite das editoras da Revista Cenário para que fosse escrito um ensaio sobre como vemos a relação entre a pandemia do coronavírus e o setor de turismo. As reflexões foram feitas a partir das experiências dos autores que, no momento da redação, residiam em três países: Brasil, Costa Rica e Estados Unidos. O texto foi escrito entre 10 de maio e 10 de junho de 2020, período no qual o Brasil e os Estados Unidos se tornaram epicentros da pandemia e a Costa Rica se tornou modelo mundial de correta gestão da crise sanitária mundial. O artigo reflete sobre a importância de se compreender o histórico mundial de crises que afetaram o turismo nos últimos 50 anos. Discute a perspectiva de como um problema que era atual no turismo - o overtourism perdeu importância e significado de forma abrupta, justamente pelo surgimento de outro problema radical - a redução, ou quase estagnação total, das viagens mundiais. Apresenta a perspectiva que se impõe ao turismo agora uma reformulação do setor, inclusive com forte apelo à sustentabilidade e à distribuição mais igualitária das riquezas por ele geradas. $\mathrm{O}$ ensaio deliberadamente não apresenta previsões sobre o turismo, mas sim aponta uma série de questões sobre 0 momento atual e sobre a possibilidade de retorno à "normalidade".
\end{abstract}

Palavras Chave: overtourism; estagnação; coronavírus; impactos no turismo.

Resumen: Este texto surgió de la invitación de las editoras de la Revista Cenário para escribir un ensayo sobre cómo vemos la relación entre la pandemia de coronavirus y el sector turístico. Las reflexiones se hicieron a partir de las experiencias de los autores que, en el momento de escribir este artículo, vivían en tres países: Brasil, Costa Rica y Estados Unidos. El texto fue escrito entre el 10 de mayo y el 10 de junio de 2020, un período en el que Brasil y Estados Unidos se convirtieron en epicentros de la pandemia y Costa Rica se convirtió en un modelo mundial para el manejo correcto de la crisis de salud global. El artículo reflexiona sobre la importancia de comprender la historia mundial de las crisis que han afectado al turismo en los últimos 50 años. Discute la perspectiva de cómo un problema que era actual en el turismo, el overtourism, perdió importancia y significado abruptamente, precisamente debido a la aparición de otro problema radical: la reducción, o el

\footnotetext{
${ }_{1}^{1}$ Professor Livre-Docente na Escola de Artes, Ciências e Humanidades de São Paulo (EACH-USP). ORCID: https://orcid.org/0000-0002-9362-6795 E-mail: panosso@usp.br

${ }_{2}^{2}$ Mestranda em Turismo na Escola de Artes, Ciências e Humanidades de São Paulo (EACH-USP). ORCID: https://orcid.org/0000-0003-4186-9389. E-mail: laizeoliveira@usp.br.

3 Pós-doutoranda na Escola de Artes, Ciências e Humanidades de São Paulo (EACH-USP). ORCID: https://orcid.org/0000-0003-2556-3806 E-mail: valferraz@usp.br
} 


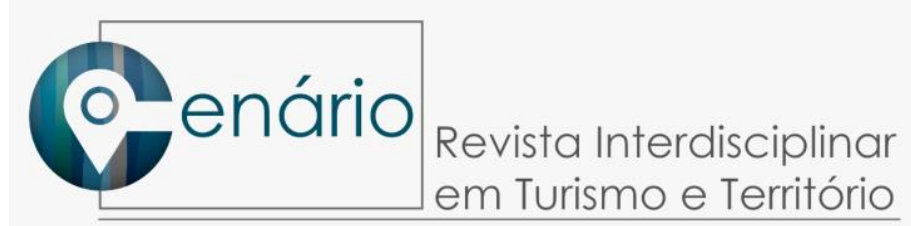

estancamiento casi total, de los viajes mundiales. Presenta la perspectiva de que el turismo necesita ser reformulado ahora, incluyendo un fuerte atractivo para la sostenibilidad y una distribución más equitativa de la riqueza que genera. El ensayo deliberadamente no presenta predicciones sobre el turismo, sino que señala una serie de preguntas sobre el momento actual y sobre la posibilidad de volver a la "normalidad".

Palabras Clave: overtourism; estancamiento; coronavirus; impactos en el turismo.

Abstract: By the invitation of the sponsors of Revista Cenário, we wrote this article. It treats our vision of the relationship between coronavirus pandemic and tourism sector. The reflections were made from the experiences of the authors who, at the time of writing, were living in three countries: Brazil, Costa Rica and the United States. The text was written between May 10th and June 10th of 2020, period when Brazil and the United States were become the epicenter of the pandemic, and Costa Rica was became the model for dealing with the global health crisis. The paper reflects the importance of understanding the world crisis history that has affected tourism in the last 50 years. It discusses the perspective of a problem that was current in tourism - overtourism, that abruptly lost importance and meaning, precisely after the emergence of another radical problem - a reduction, or almost total stagnation, in world travels. It presents a perspective that imposes on tourism nowadays the reformulation of the sector, including a strong appeal to sustainability and an equal distribution of the wealth generated by it. The essay does not presents tourism predictions, but points out issues about the current moment and the possibility of returning to "normality".

Keywords: overtourism; stagnation; coronavirus; impacts on tourism.

\section{PREÂMBULO}

Este não é um texto que faz previsões para o setor de turismo. Tampouco é uma pesquisa acadêmica que seguiu todos os passos que o método científico exige. Foi redigido no calor da pandemia do coronavírus Sars-Cov-2 (Covid-19) na América Latina, entre maio e junho de 2020. Escrevemos a convite das editoras da Revista Cenário para apresentar um "texto ou ensaio, reflexivo e crítico, sobre a questão do turismo x pandemia Covid-19."

No momento em que elaboramos este artigo, um dos co-autores, Alexandre, estava em isolamento no interior da Costa Rica, na província de Guanacaste. Entre fevereiro e julho de 2020 ele morou na Costa Rica para atender ao convite da Universidad Nacional da Costa Rica-UNA para ser professor visitante internacional. A condição de ter estado fora do Brasil não deixou o co-autor alheio aos problemas que o país enfrentou e enfrenta em decorrência da pandemia. Mesmo distante, esteve atento ao que se passava na terra natal, mas ao mesmo tempo teve a oportunidade de conviver com outras pessoas estudiosas do turismo e áreas afins que ofereceram suas visões sobre o momento vivido. A co-autora J. Laize, moradora de Santos-SP, iniciava seus estudos no curso de Mestrado do Programa de PósGraduação em Turismo da EACH-USP, na cidade de São Paulo. As aulas iniciaram de forma presencial, mas em meados de março passaram a ser virtuais com vários professores do programa e propiciaram uma visão do contexto vivido e sofrido pelo turismo nacional, tanto em seus aspectos privados quanto públicos. As leituras e os debates oportunizaram o aprofundamento e a tentativa de compreender o momento, não necessariamente oferecendo respostas aos problemas identificados, mas, muito mais, oferecendo condições para se fazerem as perguntas corretas. Por sua vez, a co-autora Valéria, pós-doutoranda no Programa de Pós-Graduação em Turismo da EACH-USP, vive na cidade de Ann Arbor (MI, EUA) e está acostumada com essa realidade virtual. O pós-doutorado que ela desenvolve utiliza dados primários já coletados no Brasil e vem permitindo que faça essa primeira parte de sua pesquisa à distância. $O$ uso da tecnologia (chats e videoconferências) vem proporcionando orientações on-line e ajudando a pesquisadora a seguir com suas atividades acadêmicas. 


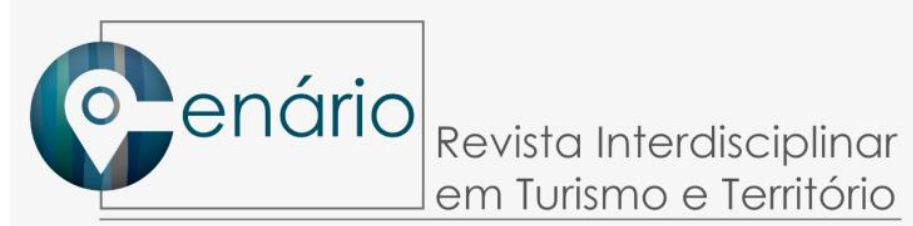

Tentamos, portanto, aproveitar essas oportunidades de diversidade de vivências, olhares e lugares para aprimorar nossa análise sobre a relação do turismo com o Covid-19. Este foi o contexto de redação deste ensaio.

\section{INTRODUÇÃO}

É interessante (e até estranho) perceber que até fins de 2019 um dos temas mais atuais nos estudos turísticos era o "overtourism" (BENI, 2020; HUETE, 2018; ZERVA et al. 2019; ALCALDE et al. 2018). Segundo uma publicação de 2018 viabilizada pela Organização Mundial do Turismo, pela Universidade de Breda e pela Universidade de Ciências Aplicadas de Stenden, overtourism é "o impacto do turismo em um destino, ou em partes dele, que afeta excessivamente a percepção da qualidade de vida dos cidadãos e/ou a qualidade das experiências dos visitantes de forma negativa" (p. 4). Esta mesma publicação reconhece que o termo havia sido cunhado um pouco antes, por Skift (2016) e que existem muitas definições, inclusive cita a proposta pelo Responsible Tourism Partnership (www.responsibletourismpartnership.org/overtourism) que se refere ao "overtourism" como:

Destinos em que anfitriões ou convidados, moradores ou visitantes, sentem que há muitos visitantes e que a qualidade de vida na área ou a qualidade da experiência se deterioraram inaceitavelmente. É o oposto do Turismo Responsável, que consiste em usar o turismo para criar melhores lugares para morar e lugares para visitar. Muitas vezes, visitantes e convidados experimentam a deterioração simultaneamente (SKIFT, 2016, n.p.).

Em muitos eventos científicos de turismo este era o tema principal. Ele se relaciona com os impactos negativos do turismo; a capacidade de análise da imensa quantidade de dados gerados pelos sistemas de informação; as previsões, ações e projetos de como minimizar os impactos; vários livros temáticos, paper em revistas científicas, etc. Somente como referência, uma busca no Google scholar com o termo "overtourism" (https://scholar.google.com/scholar?hl=pt-BR\&as sdt=0\%2C5\&q=\%22overtourism\%22\&oq=) em 5 de junho de 2020 mostrou 2.100 resultados.

Mas qual a relação do "overtourism" com a pandemia do coronavírus e seus impactos no turismo? Bom, talvez a relação seja o ensinamento de como o turismo é um setor vulnerável; que as previsões, apesar de gozarem de certa confiabilidade no momento em que são lançadas, são também facilmente descartadas; que no momento de auge da pandemia - primeiro semestre de 2020 - com a paralisação dos voos, fechamento de fronteiras internacionais, isolamentos e quarentenas recomendados ou forçados, e com a limitação das mobilidades, percebamos o quanto o turismo é importante. Uma atividade que nem sempre é valorizada pelos setores sociais como atividade econômica, social, cultural e como área de estudos, mas quando é impedida de ser realizada, sentimos sua ausência, daí que ela evidencia seu poder.

Essa reflexão inicial nos remete à introdução do livro "Grundriss der Allgemeinen Fremdenverkehrslehre" ("Tratado de uma teoria geral do turismo", numa tradução livre) de Hunziker e Krapf, publicado em 1942, na Suíça, em plena II Guerra Mundial. Eles afirmaram naquela introdução que "à primeira vista pode parecer algo inoportuno, ou ao menos pouco urgente publicar neste momento [em plena guerra] uma obra com este carácter" (p.5, tradução livre), mas justificaram em seguida a decisão dizendo que "a isto poderiam contrapor o fato de que precisamente as circunstâncias difíceis da atualidade ressaltam com uma claridade especial a importância do turismo" (p.5, tradução livre) e decretam, usando inicialmente uma passagem de Dante Alighieri:

Non c'e piú grand dolore che ricordarsi del tempo felice nella miseria, que a pessoa agora se dá conta claramente do grande papel que desempenha o turismo, em tempos mais normais, para o indivíduo, para a vida da 
comunidade e para a vida de um país. Se reconhece também em maior medida a necessidade de dedicar ao turismo - quanto retornem às circunstâncias normais - a intensa atenção e cuidado que ele merece (HUNZIKER, KRAPF, 1942, p.5, tradução livre).

Este contraponto do overtourism à estagnação também nos leva a outra questão: a "monocultura do turismo". O setor de turismo é dependente do sistema capitalista, pois é fruto do capitalismo, da industrialização que se fortalecia no segundo quartel do século XIX, da criação de meios de transportes mais rápidos (trens e barcos a vapor), do surgimento de uma classe burguesa que usufruía da mais valia e tinha tempo livre para empreender viagens. O fato é que hoje, com tal pandemia, essa dependência do turismo do capital parece mostrar seu lado mais frágil. Se de um lado, a economia local se desenvolve a partir da cadeia produtiva do setor, de outro ela fica à mercê do fluxo contínuo de turistas - que em momentos de crise desaparecem. Seria esse o momento de pensar o turismo somente como uma atividade econômica complementar? Países altamente dependentes economicamente do turismo, tais como Espanha, França, Itália e Costa Rica estão descobrindo isso da forma mais dura. Tornou-se senso comum afirmar que o setor de turismo foi o primeiro a parar e será o último a retornar à normalidade. "Normalidade" aqui entendida, ou ao menos divulgada, como aquele vai e vem de pessoas lotando os destinos mais famosos e causando um grande impacto, conhecido recentemente como... overtourism.

O reconhecimento da importância de se estudar os fluxos turísticos locais e globais pode ser um fator preponderante neste momento, tal como já apresentaram Pieri e Panosso Netto (2015). Segundo esses autores, no âmbito local os impactos positivos e negativos e as questões de planejamento e gestão do setor seriam os mais temas mais estudados. No âmbito regional ou global são observadas a maior participação do poder público, a forma de gestão centralizada ou descentralizada e a decisão se o turismo é ou não um setor importante para os países em questão.

Mas não somente a parte econômica do turismo deve ser revista, senão toda a "maquinaria das viagens", numa clara referência à crítica feita por Jost Krippendorf ([1984] 2009) no início dos anos 1980. Sobre esta mesma questão Trigo e Panosso Netto (2003 e 2009) se manifestaram e apresentaram algumas "Reflexões sobre um novo turismo" (2003) e, em seguida, ampliaram seu texto apontando os rumos que deveria ter esse "novo turismo":

O setor de viagens e turismo é um dos mais significativos da economia global; portanto, é importante enquanto construtor de uma nova ordem internacional. O turismo depende de uma sociedade equilibrada e justa para se desenvolver plenamente. Outro tipo de turismo será possível apenas em uma sociedade mais participativa. Capital e conhecimento são importantes nessa construção, mas a revalorização do humanismo é fundamental para que a vida seja preservada e dignificada. A vida humana, a vida animal e vegetal e o próprio planeta, que sustenta todas essas vidas, são os nossos maiores valores. O restante, ou seja, o dinheiro e a capacidade intelectual, devem estar subordinados à vida da maioria, conforme todas as religiões e filosofias simbióticas preconizam há milênios. A humanidade realiza uma viagem pelo planeta que já conta 100 mil anos. Houve um imenso progresso material e intelectual nesse período, em comparação com os primeiros hominídeos, mas o mesmo não aconteceu com o progresso da consciência de que o planeta é a casa de todos os homens e mulheres, da vida em geral que já estava presente antes mesmo que os primatas aparecessem (PANOSSO NETTO; TRIGO, 2009).

Dizer como deve ser ou deveria ser o turismo não implica em apontar tendências de mercado. Não nos propomos a isso neste momento tão complicado. Porém, é fato que todos os anos quando os professores iniciam as aulas nos cursos de turismo nas universidades, 


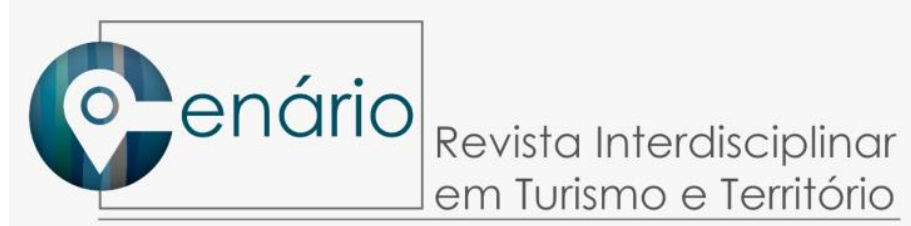

geralmente apresentam as tendências para o setor de turismo naquele ano ou nos anos vindouros. Em 2020, a previsões feitas em janeiro, antes mesmo de terminar o mês já estavam defasadas ou de nada valiam. Apresentamos dois grupos de tendências apenas para demonstrar que tentar prever como será a atividade turística daqui para frente, como se comportarão os turistas, as comunidades receptoras, os governos e empresários do setor, é algo inviável, ao menos a médios e longos prazos. Tais tendências para o turismo em 2020 foram publicadas em veículos de comunicação do Brasil em janeiro de 2020 e estão no Quadro 1.

Quadro 1. Tendências para o turismo 2020 segundo Consumidor Moderno e Booking

\begin{tabular}{|c|c|}
\hline Grupo I* & Grupo II** \\
\hline A invasão da Geração Z. & Aumento de destinos secundários. \\
\hline Turismo de bem-estar para os mais velhos. & Tecnologia de viagens. \\
\hline Equilíbrio contra o excesso de turistas. & Viaje com calma. \\
\hline Novas rotas dos voos super longos. & Total de experiências. \\
\hline \multirow[t]{4}{*}{ "Flight shaming". } & Viaje com animais de estimação. \\
\hline & Escapadas para (se sentir) jovem. \\
\hline & Reservas de restaurantes em viagens. \\
\hline & Planos de viagem de longo prazo. \\
\hline
\end{tabular}

Num rápido olhar se percebe que estas 13 tendências não se mantiveram atuais nem por 30 dias. Em fins de janeiro 0 vírus chegou ao Brasil (https://oglobo.globo.com/sociedade/ministerio-da-saude-descobre-que-coronavirus-chegouao-brasil-em-janeiro-1-24347029) e isso nos leva a crer que nesta situação de olhar para trás pode ser necessária e didática.

Ao que tudo indica esta crise atual é a mais dura enfrentada pela história recente da humanidade, e se compara às grandes guerras do século $X X$ e à pandemia da gripe espanhola de 1918. Contudo, em nosso campo de estudos cabe ressaltar que, ainda que tais comparações sejam limitadas se considerarmos o período de ascensão do turismo contemporâneo, é importante ter em mente, ou olhar no retrovisor, para perceber que outras crises trouxeram impactos no turismo, seja em aspectos mundiais, continentais ou regionais.

Importa perceber que o turista é afetado em suas decisões de viagens por fatores subjetivos e objetivos. Os fatores subjetivos podem ser o medo, o receio, a falta de vontade de ir a um lugar, as crenças políticas ou religiosas, etc. Os fatores objetivos são os que se apresentam externamente e são percebidos não só por um sujeito, mas sim por um grupo de sujeitos. Portanto, mudanças globais são questões que afetam não só o turismo, mas toda a mobilidade e as ações das populações.

Essas mudanças globais podem, inclusive, nos fazer refletir e pensar em previsões para além dos dados estatísticos e econômicos. Talvez esse seja um momento de passarmos a medir o sucesso do turismo não mais em função dos quilômetros viajados, dos dólares gastos ou dos números de viagens feitas, mas levando em consideração dados como a distribuição de renda e a satisfação e alegria per capita dos residentes. Os benefícios da atividade turística precisam ser percebidos por toda a população, de forma 


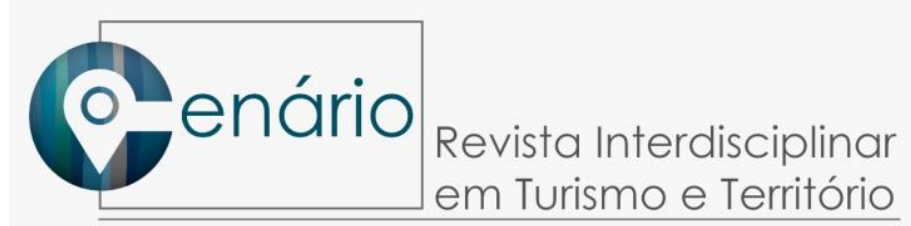

equilibrada. Os turistas precisam se adaptar aos costumes locais e não a população local se adaptar aos costumes dos turistas.

Como exemplo do que temos argumentado, temos o co-autor Alexandre que vive durante a redação deste texto na Costa Rica "profunda", numa pequena cidade que não é propriamente turística, mas está próxima de atrações turísticas internacionais (praias, resorts, parques naturais). Sendo estrangeiro, seu comportamento está integrado com o povo simples do local. Come os pratos que Ihe são oferecidos; utiliza exclusivamente um dos principais meios de transporte locais, a bicicleta; e, sendo um dos poucos "turistas" residentes na cidade, já é conhecido por muitos moradores em seus roteiros de final de tarde e de fim de semana de bike por estradinhas de cascalho que levam aos parques e reservas naturais mais próximos.

Por sua vez a co-autora Valéria, que reside em um "college city", vivencia as contradições de uma cidade que possui boa parte da população vinculada às atividades da universidade. No caso de Ann Arbor, que possui 115 mil habitantes, a estimativa é que cerca de 30 mil pessoas trabalhem nos campus e centros de pesquisa da Universidade de Michigan e que aproximadamente $32 \%$ da população seja formada por estudantes e professores. Essa diversidade de pessoas contribui para a formação de um ambiente acolhedor e cosmopolita. Contudo, o período escolar americano (que vai de setembro a maio) coincide com o inverno rigoroso da Região dos Lagos da América do Norte. Com isso, durante boa parte do ano as pessoas realizam suas atividades "in-door" (lugares fechados). $E$, durante o verão, época do ano onde a cidade fica mais bonita e quando é possível usufruir de fato o espaço público, a cidade permanece "vazia", pois os estudantes e professores voltam para suas cidades de origem. Por conta da pandemia, o "esvaziamento temporário" da cidade começou mais cedo, em março, mês em que as aulas da universidade foram suspensas.

E a co-autora J. Laize, que vive na região turística denominada Costa da Mata Atlântica (conhecida como Baixada Santista, Figura 1), no litoral sul do Estado de São Paulo, percebe o modo como a demanda elevada afeta direta o cotidiano dos residentes das nove cidades que compõem o mapa turístico regional. Apenas para citar como exemplo, em períodos de alta temporada, filas gigantescas em serviços essenciais integrados à atividade turística e o planejamento urbano impreciso "forçam" os residentes a adaptarem hábitos rotineiros ao fluxo de visitantes. De outro modo, a relação entre os benefícios quantitativos e qualitativos em torno dos efeitos da demanda excessiva nos nove destinos coloca em debate outras questões que incomodam os residentes, como o aumento de resíduos sólidos nas praias, elevação de preços em produtos/serviços essenciais, superlotação de automóveis, ou a segregação em bairros tradicionais. Isso tudo leva por vezes o residente a se perguntar se vale a pena receber tantos turistas que desfrutam ao máximo do local, deixando benefícios difíceis de se evidenciarem com clareza.

Figura 1. Praia de Santos-SP sem público devido à pandemia em abril de 2020.

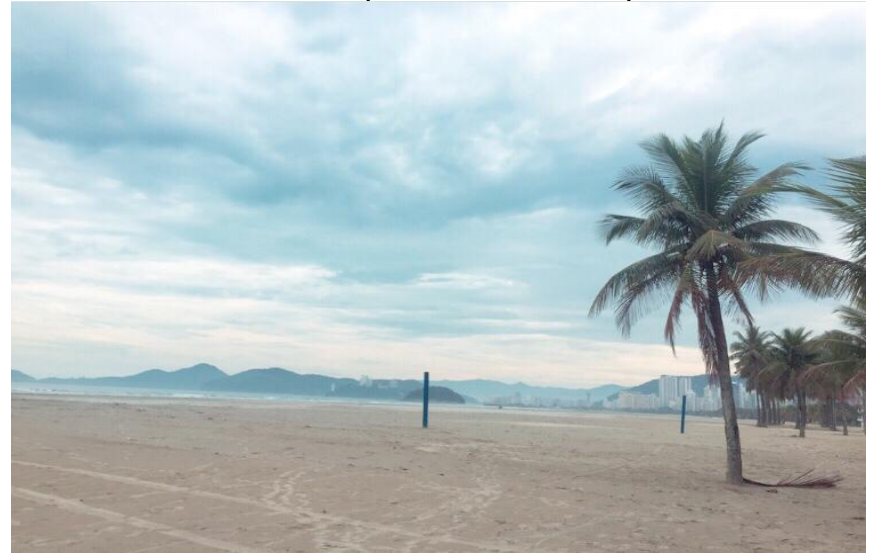

Fonte: Autores (2020). 


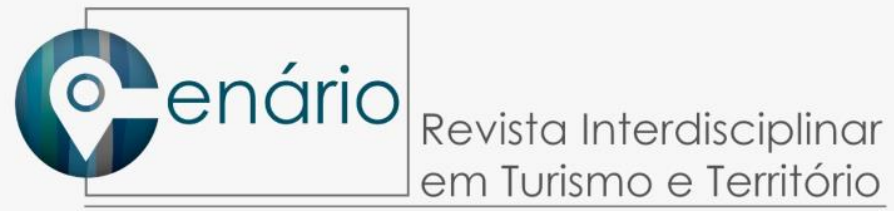

Não foram somente as pandemias que afetaram o turismo mundial nos últimos 50 anos. É importante compreender que as crises e mudanças globais ocorrem com mais frequência que imaginamos e que influem em todos os aspectos da vida humana. Numa rápida busca na internet encontramos uma série de crises globais/regionais que afetam o turismo de forma negativa desde 1970 (Quadro 2).

Algumas vezes o impacto foi prolongado, noutras mais rápido, e o setor se recuperou, ao menos economicamente.

Quadro 2. Relação de crises globais/regionais que afetam o turismo de forma negativa desde 1970.

\begin{tabular}{|c|c|}
\hline Crises & Consequências \\
\hline $\begin{array}{l}\text { Crises políticas } \\
\text { (distúrbios políticos, } \\
\text { ações terroristas, } \\
\text { guerras e } \\
\text { enfraquecimento das } \\
\text { democracias) }\end{array}$ & $\begin{array}{l}\text { - } \quad \text { Guerra do Golfo Pérsico (1991) } \\
\text { - } \quad \text { Ataerras de Bósnia e Kosovo }(1992-1996) \\
\text { - } \quad \text { Ataque ao Metrô gêmeas em NY Madrid, Espanha (2004) } \\
\text { - } \quad \text { P Primavera Árabe-2010-2012; }\end{array}$ \\
\hline $\begin{array}{l}\text { Crises humanitárias e } \\
\text { sanitárias }\end{array}$ & $\begin{array}{l}\text { - } \text { Migrações em massa de refugiados (norte da África, p.ex.) } \\
\text { - } \quad \text { PAbreza extrema (Haiti, Burundi, Congo, Malawi, etc.) } \\
\text { - } \text { H1N1-2003 } \\
\text { - Covid-19 }\end{array}$ \\
\hline Crises econômicas & $\begin{array}{l}\text { - } \quad \text { Crise do petróleo (1973) } \\
\text { - } \quad \text { Cisputa Iraque-Irã (1980) } \\
\text { - } \quad \text { Crise do Peso Mexicano (1994) } \\
\text { - } \quad \text { Corralito na Argentina (2001) }\end{array}$ \\
\hline $\begin{array}{l}\text { Mudanças climáticas } \\
\text { bruscas }\end{array}$ & $\begin{array}{l}\text { - } \text { Desertificação } \\
\text { - } \quad \text { Aquos aos corais marinhos } \\
\text { - } \quad \text { Tempestades }\end{array}$ \\
\hline $\begin{array}{lr}\text { Movimentos } & \text { da } \\
\text { natureza } & \text { (furacões, } \\
\text { terremotos } & \text { e } \\
\text { tsunamis) } & \end{array}$ & $\begin{array}{l}\text { - } \quad \text { Tsunami da Indonésia (2004) } \\
\text { - } \quad \text { Furacão Wilma e Katrina, EUA (2005) } \\
\text { - } \quad \text { Terremoto no Haiti (2010) } \\
\text { - Tsunami do Japão (2011) }\end{array}$ \\
\hline
\end{tabular}

Fonte: Elaborado pelos autores a partir de consulta livre a sites e artigos científicos variados (2020)

Somente no caso de pandemias ou doenças, no século $X X$ foram 12 as principais nos últimos 100 anos, segundo C. Michael Hall, Daniel Scott \& Stefan Gössling (2020, p. 56) (Quadro 3).

Quadro 3. Grandes pandemias e surtos de doenças

\begin{tabular}{|l|l|l|l|}
\hline Data & \multicolumn{1}{|c|}{ Doenças } & \multicolumn{1}{|c|}{ Casos e mortes } & Observações \\
\hline $\begin{array}{l}1918 \\
\text { até } \\
1920\end{array}$ & $\begin{array}{l}\text { Gripe Espanhola } \\
\text { (Influenza) }\end{array}$ & $\begin{array}{l}500 \text { milhões de } \\
\text { casos e 21 a 100 } \\
\text { milhões de mortes }\end{array}$ & $\begin{array}{l}\text { A gripe espanhola afetou 1/3 da população } \\
\text { mundial e matou de 1 a 5\% da população, } \\
\text { excedendo em muito o número de mortos na } \\
\text { Primeira Guerra Mundial. }\end{array}$ \\
\hline
\end{tabular}


1957 Gripe Asiática

até (Influenza)

1958
De 1 a 2 milhões de mortes

\begin{tabular}{|l|l|}
\hline $\begin{array}{l}1968 \\
\text { até } \\
1969\end{array}$ & $\begin{array}{l}\text { Gripe de Hong } \\
\text { Kong } \\
\text { (Influenza) }\end{array}$ \\
\hline $\begin{array}{l}1960 \\
\text { até } \\
\text { hoje }\end{array}$ & $\begin{array}{l}\text { Infecção pelo vírus } \\
\text { da } \\
\text { imunodeficiência } \\
\text { humana e } \\
\text { síndrome da } \\
\text { imunodeficiência } \\
\text { adquirida } \\
\text { (HIV/AIDS) }\end{array}$ \\
\hline
\end{tabular}

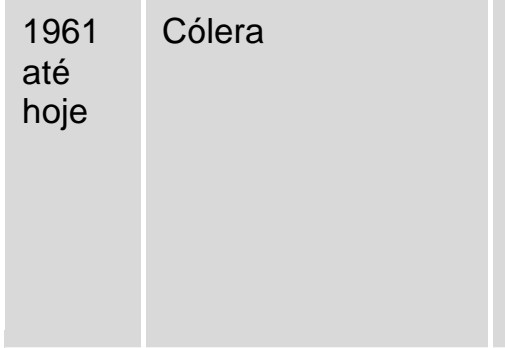

2000 SARS

até (Coronavírus)

2003
De 500 mil a 2 milhões de mortes

70 milhões de casos e 35 milhões de mortes (principalmente na Africa)

De 1,4 a 4 milhões de casos por ano e de 21 mil a 143 mil mortes por ano

Cerca de $8 \mathrm{mil}$ casos e 750 mortes

A OMS (Organização Mundial da Saúde) estimou, em 2009, que entre 1 a 4 milhões de pessoas morreram. Como resultado da pandemia, houve uma queda de $-3,5 \%$ a $0,4 \%$ no PIB global.

Desenvolvimento acelerado de uma vacina que limita a disseminação da cepa responsável.

Essa foi a primeira vez que o vírus se espalhou extensivamente pelo mundo, devido às viagens aéreas. A OMS (2009) estimou, em 2009, uma queda do PIB global de $-0,4$ a $-1,5 \%$.

O primeiro caso conhecido foi em 1959. Identificado pela primeira vez em 1983.

A diminuição da expectativa de vida em muitos países africanos como resultado do HIV (AIDS) está associada a uma redução estimada das taxas de crescimento econômico em -0,3 a $1,5 \%$.

Os surtos de cólera afetam negativamente a demanda doméstica e internacional de serviços da indústria do turismo dos países afetados. A sétima pandemia de cólera começou no sul da Ásia em 1961. Recentes surtos notáveis incluem os do Zimbábue (2008-2009), Haiti (2010 até o presente) e lêmen (2016 até o presente).

Custo econômico global estimado em US \$ 100 bilhões e US \$ 48 bilhões somente na China. Originadas na China, as viagens internacionais permitiram que o vírus da SARS se espalhasse para 37 países.

\begin{tabular}{|l|l|l|}
\hline 2009 & $\begin{array}{l}\text { Gripe Suína } \\
\text { (Influenza) }\end{array}$ & 284 mil mortes \\
\hline 2012 & $\begin{array}{l}\text { Síndrome } \\
\text { Respiratória do } \\
\text { Oriente Médio } \\
\text { (MERS-CoV } \\
\text { coronavírus) }\end{array}$ & $\begin{array}{l}\text { Taxa de letalidade } \\
\text { de 35\% }\end{array}$ \\
\hline
\end{tabular}

O impacto econômico do surto da doença no México, onde começou a pandemia, foi estimado em US \$3,2 bilhões (0,3\% do PNB PIB Nacional Bruto), com perdas no setor do turismo estimadas em US $\$ 2,8$ bilhões.

Transmitido por camelos e humanos.

Nenhuma vacina disponível. Em 2015 o surto de MERS na Coreia resultou em uma perda estimada em US \$2,6 bilhões para o setor do turismo. As recomendações para se evitar contrair a doença ainda continuam válidas para aqueles que fazem peregrinação de hajj e umrah à Arábia Saudita.

\begin{tabular}{|c|c|}
\hline $\begin{array}{l}2014 \\
\text { até } \\
\text { hoje }\end{array}$ & $\begin{array}{l}\text { Ebola } \\
\text { (Febre } \\
\text { Hemorrágica) } \\
\text { África Ocidental } \\
\text { (principalmente } \\
\text { Guiné, Libéria, }\end{array}$ \\
\hline
\end{tabular}

Cerca de 28,5 mil casos e 11,3 mortes reportados (números provavelmente subestimados)
Causada por vírus transmitido de animais selvagens, com taxa de letalidade de até $90 \%$ (média de $50 \%$ ).

A vacina contra o Ebola já está disponível. As estimativas de queda do PIB, devido ao surto na África Ocidental, variam de US $\$ 2,8$ a US $\$$ 


\begin{tabular}{|c|c|c|c|}
\hline & $\begin{array}{l}\text { Serra Leoa e } \\
\text { Congo). }\end{array}$ & & 32,6 bilhões. \\
\hline $\begin{array}{l}2015 \\
\text { até } \\
\text { hoje }\end{array}$ & $\begin{array}{l}\text { Zika (Américas, } \\
\text { principalmente no } \\
\text { Brasil; flavivírus } \\
\text { transmitido } \\
\text { principalmente por } \\
\text { mosquitos Aedes } \\
\text { aegypti) }\end{array}$ & $\begin{array}{l}\text { Número } \\
\text { desconhecido de } \\
\text { casos. Poucas } \\
\text { mortes. Contudo, a } \\
\text { doença pode } \\
\text { resultar em } \\
\text { microcefalia em } \\
\text { bebês nascidos de } \\
\text { mães infectadas e } \\
\text { na síndrome de } \\
\text { Guillain-Barré. }\end{array}$ & $\begin{array}{l}\text { Nenhuma vacina disponível. } \\
\text { O Banco Mundial estima que o impacto em } \\
\text { curto prazo do surto de Zika para } 2016 \text { na } \\
\text { América Latina e no Caribe foi de cerca de US \$ } \\
3,5 \text { bilhões. Isso porque o turismo é um setor } \\
\text { significativo para a economia local desses } \\
\text { países e nessa época estavam sendo } \\
\text { realizados grandes eventos esportivos. }\end{array}$ \\
\hline $\begin{array}{l}2016 \\
\text { até } \\
\text { hoje }\end{array}$ & Dengue & $\begin{array}{l}100 \text { milhões } \text { de } \\
\text { casos e } 38 \text { mil } \\
\text { mortes }\end{array}$ & $\begin{array}{l}\text { A dengue é uma doença viral transmitida pela } \\
\text { picada do mosquito Aedes aegypti - o mesmo } \\
\text { mosquito capaz de transmitir a humanos as } \\
\text { doenças como chikungunya e zika. Tem uma } \\
\text { taxa de letalidade alta e consequente influência } \\
\text { na economia local. O custo global anual total } \\
\text { da dengue em } 2013 \text { foi estimado em US } \$ 89 \\
\text { bilhões. } \\
\text { Os surtos ocorrem periodicamente, mas o surto } \\
\text { de } 2016 \text { foi global em escala. }\end{array}$ \\
\hline $\begin{array}{l}2019 \\
\text { até } \\
\text { hoje }\end{array}$ & $\begin{array}{l}\text { Covid-19 } \\
\text { (Coronavírus) }\end{array}$ & $\begin{array}{l}\text { Em } 22 \text { de abril de } \\
2020 \text {, já havia mais } \\
\text { de } 2,5 \text { milhões de } \\
\text { casos e } 180 \text { mil } \\
\text { mortes em todo } \\
\text { planeta. Contudo, } \\
\text { estima-se que haja } \\
\text { uma subnotificação } \\
\text { significativa. }\end{array}$ & $\begin{array}{l}\text { Em função do isolamento social, tida como a } \\
\text { única medida efetiva capaz de evitar a } \\
\text { contaminação em massa, o setor do turismo } \\
\text { vem registrando perdas expressivas de renda e } \\
\text { geração de empregos. O Conselho Mundial de } \\
\text { Viagens e Turismo (WTTC, 2020) prevê uma } \\
\text { perda relacionada ao turismo de até US } \$ 2,1 \\
\text { trilhões em } 2020 \text { e até } 75 \text { milhões de empregos }\end{array}$ \\
\hline
\end{tabular}

Fonte: C. Michael Hall, Daniel Scott \& Stefan Gössling (2020, p. 5-6), fundamentados em: Aleeban \& Mackey, 2016; Al-Tawfiq et al., 2014; Bell et al., 2003; Bloom \& Cadarette, 2019; Girard et al., 2010; Gubler, 2012; Huber et al., 2018; Joo et al., 2019; Kirigia et al., 2009; Petersen et al., 2016; Rassy \& Smith, 2013; Shepard et al., 2016; Siu \& Wong, 2004; Taubenberger \& Morens, 2006; WHO, 2009; World Bank, 2016; WTTC, 2020.

O Quadro 3 evidencia 12 patologias e pandemias nos últimos 100 anos, sendo que 7 delas ainda existem e se proliferam (AIDS, Cólera, MERS-CoV, Ebola, Zika, Dengue e Covid-19). Esse olhar ao passado, ao retrovisor, nos ensina mais uma vez que os acontecimentos históricos não são lineares, mas cíclicos, acidentados, suscetíveis às ações da natureza e dos próprios homens. De certa forma, seria um chamado para tentarmos aprender algo com este momento conturbado, confuso, incerto e inseguro que todos estamos vivendo. Ter essa consciência pode ajudar no processo de decisão dos governantes sobre quais ações devem tomar para protegerem seus povos, suas economias, as sociedades e a vida em sua forma mais ampla. 


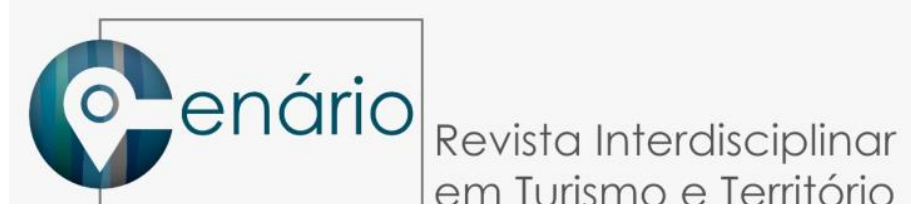

\section{COMO OS PAÍSES TÊM ENFRENTADO A PANDEMIA EM TERMOS DE TURISMO?}

As questões em torno da crise sanitária induzida pelo Covid-19 permeiam previsões e incertezas. Diante de um fenômeno que não pertence exclusivamente ao domínio da saúde pública, medidas não farmacológicas estabelecem como estratégias de combate ações rigorosas: populações em quarentena, isolamento e distanciamento social, e em último caso, o polêmico lockdown. Tais medidas afetam diversos setores da economia global e promovem discussões em diferentes contextos.

No setor de turismo, a paralisação do fluxo de turistas no mapa mundial estima uma perda entre 300-450 bilhões de euros (OMT, 2020). Pensando nos prazos curto, médio e longo, torna-se viável a análise conjuntural das ações entre os países afetados para uma visão amplificada sobre a sustentabilidade no setor, a fim de propor soluções articuladas, considerando o turismo como um dos campos mais globalizados da economia. É, portanto, um momento histórico oportuno para que as práticas adotadas até então sejam repensadas e, dependendo da situação, substituídas por outras que respondam melhor aos anseios da sociedade.

Com exceção da Antártida, que é o único continente sem registrar casos da doença até o momento, os demais continentes apresentam quadros conjunturais extremos entre os países nos vetores de controle dos contágios. Enquanto alguns países destacam-se pelo modelo exemplar de gestão da crise por terem reconhecido a existência da doença de imediato e tomado medidas recomendadas pelas instituições oficiais e cientistas, outros se destacam pela péssima gestão justamente por não reconhecerem a pandemia de imediato e não adotarem as medidas recomendadas pelas instituições que entendem do tema. Nas Américas e Europa, a gestão da pandemia coloca em destaque negativo países como Equador, México, Espanha e Itália, com destaque especial aos Estados Unidos, com o maior número de casos de enfermos e de mortos e ao Brasil, epicentro mundial da doença nos últimos dias de maio de 2020. Países como Taiwan, Noruega e Nova Zelândia tornaram-se exemplos de ações efetivas contra a pandemia. Países que não seguiram as orientações propostas pelos órgãos mundiais de saúde como Espanha, Itália e Brasil, foram falhos e tornaram-se restritivos. Ainda assim, diante da gravidade de expansão do contágio, países com problemas de gestão ultrapassam picos e continuam a fracassar em suas ações, colocando regiões em rota de lockdown. Este é o caso específico do Brasil no momento da redação deste texto (segunda quinzena de maio de 2020).

No contexto do turismo, as ações promovidas nos diferentes países refletem preocupações tanto no panorama econômico quanto social. Alguns noticiários ao redor do mundo exemplificam dois extremos na estrutura de combate à crise frente às ações de recuperação do turismo: fatores potenciais de impactos positivos, ou negativos (quadro 4).

Quadro 4. Exemplos de notícias sobre o cenário do turismo frente à pandemia do Covid-19.

\begin{tabular}{|c|l|c|c|}
\hline Data & \multicolumn{1}{|c|}{ Título } & Canal & Autor \\
\hline $20 / 02 / 2020$ & $\begin{array}{l}\text { "Could coronavirus push global tourism to the } \\
\text { brink?" }\end{array}$ & The Times & Wallace \\
\hline $17 / 03 / 2020$ & $\begin{array}{l}\text { "Coronavirus-fuelled tourism meltdown yields pros } \\
\text { and cons for conservation" }\end{array}$ & $\begin{array}{r}\text { The Globe and } \\
\text { Mail }\end{array}$ & Bisby \\
\hline $31 / 03 / 2020$ & $\begin{array}{l}\text { "5 ideias do que pode mudar no Turismo pós- } \\
\text { coronavírus" }\end{array}$ & $\begin{array}{c}\text { Portal } \\
\text { Panrotas }\end{array}$ & Vieira \\
\hline $20 / 04 / 2020$ & $\begin{array}{l}\text { "How Will Covid-19 Affect Future Travel } \\
\text { "Behavior? A Travel Crisis Expert Explains" }\end{array}$ & $\begin{array}{r}\text { The New York } \\
\text { Times }\end{array}$ & Glusac \\
\hline
\end{tabular}




\begin{tabular}{|c|l|c|c|}
\hline 05/05/2020 & "Tourism Faces a Long Road Back to Normalcy” & $\begin{array}{c}\text { The Wall } \\
\text { St. Journal }\end{array}$ & Wong \\
\hline $14 / 05 / 2020$ & $\begin{array}{l}\text { "Coronavirus: Jobs lost as hotel and tour firm } \\
\text { collapses" }\end{array}$ & BBC & BBC \\
\hline $18 / 05 / 2020$ & $\begin{array}{l}\text { Los países europeos más dependientes del } \\
\text { turismo se comprometen a pactar la desescalada }\end{array}$ & El País & Abellán \\
\hline $19 / 05 / 2020$ & Coronavirus: The consequences for tourism & DW & $\begin{array}{l}\text { Kirchhoff, } \\
\text { Bonney-Cox }\end{array}$ \\
\hline
\end{tabular}

Fonte: Elaborado pelos autores.

As notícias colocam em debate novas questões relacionadas à própria existência da atividade turística. Os excessos do turismo contemporâneo (antes uma preocupação evidente) são ofuscados por ameaças em meio ao cenário de incertezas potencializado pela crise pandêmica. Entre prós e contras da atividade turística, em países como Madagascar, Nepal, Tailândia, e Zimbabué reservas de conservação de vida selvagem estão sofrendo com a caça indiscriminada de animais, intensificada pela falta de turismo, como destacou o jornal The Globe and Mail (2020). Por outro lado, a completa desaceleração no setor das viagens mundiais coloca pequenos e grandes empreendimentos em cheque e a rápida recuperação do setor pode propiciar novos debates em torno do overtourism. Neste sentido, estratégias de planejamento, redirecionamento, reinvenção e reordenamento do turismo, etc., devem estar alinhadas com a construção de políticas públicas, ações éticas, sustentabilidade, transparência na gestão para que se mantenham em equilíbrio e sejam viáveis.

Na definição de estratégias de combate à pandemia no Brasil, em integração ao Ministério do Turismo (MTur), foi criado o Centro de Operações de Emergências em Saúde Pública para o novo Coronavírus (COE-nCoV). Para o esclarecimento de dúvidas, o MTur produziu o "Manual sobre Coronavírus" com informações para turistas, profissionais e conglomerados do turismo, além da cartilha "Coronavírus: informações para o setor de viagens". A produção de informações sobre a questão do impacto da pandemia no setor do turismo auxilia na adoção de medidas frente às variáveis de alcance de recuperação do setor, apontando novas possibilidades estruturação das viagens, novos perfis de consumo, por exemplo.

No Brasil, o governo fechou fronteiras aéreas, aquaviárias e terrestres, para entrada de estrangeiros de todas as nacionalidades. Excepcional e temporária, a medida de restrição pela portaria no 255, de 22 de maio de 2020 aplica recomendações da Agência Nacional de Vigilância Sanitária (ANVISA), considerando a declaração de emergência oficial da Organização Mundial da Saúde (OMS, 30/01/2020); prevenção de riscos em situações de emergência como princípio da Política Nacional de Segurança Pública; e controle das medidas de saúde frente à pandemia. Trata-se de uma medida importante, porém tomada com certo atraso temporal.

O empenho em reerguer a economia do turismo no país está associado à proposta de estímulos financeiros às empresas do setor. Uma publicação no portal Senado Notícias oferece expectativas de recuperação do setor: "Coronavírus: turismo poderá receber incentivos fiscais durante a pandemia" (Agência Senado, 2020). Justificado pela gravidade dos impactos da pandemia no campo do turismo, o Projeto de Lei (PL) 800/2020 apoia pessoas físicas e jurídicas, os objetivos são evitar o fechamento de empreendimentos relacionados ao turismo, considerando que a pulverização da cadeia produtiva do setor contribui para a distribuição de renda em todo o país. Ao que tudo indica não há muita clareza de como será essa ajuda governamental e nem como os profissionais autônomos do turismo (agentes de viagens, guias de turismo, artesãos, turismólogos, etc.) serão 


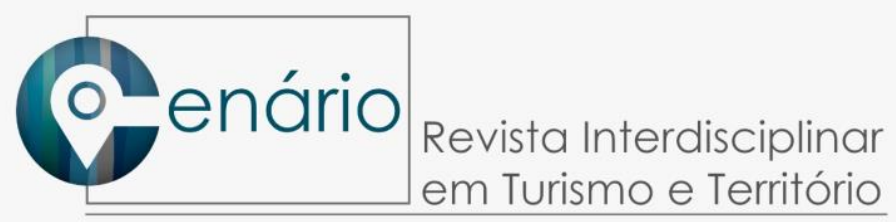

amparados. Na primeira semana de junho de 2020 este projeto ainda estava "em tramitação" no site do Senado Federal. Esse era o cenário no período.

Já no caso dos Estados Unidos, a ajuda do governo veio por meio da Lei de Auxílio, Alívio e Segurança Econômica. Sancionada no dia 27 de março deste ano, a "CARES Act" (Lei no. 116-136) é um pacote milionário de ajuda do governo para várias áreas, incluindo o turismo. A lei concede doações federais, empréstimos e benefícios fiscais a empresas do setor. O setor de transporte aéreo de passageiros, por exemplo, ao se favorecer de algum benefício, deve dar alguma contrapartida - como não demitir seus funcionários até 30 de setembro de 2020. A Lei também disponibiliza empréstimos e cobra garantia a agências de viagens, hotéis, bares e restaurantes.

Contudo, a "CARES Act" não contempla o setor de aluguel de carros, que negocia descontos ou isenção nos pagamentos devidos ao uso de espaços nos aeroportos. Tampouco as empresas de navios e cruzeiros, que têm, em sua maioria, sedes registradas em outros países. Operadores de cassinos, exceto aqueles inseridos dentro dos estabelecimentos cuja empresa principal é a hospedagem, também não são elegíveis pela Lei CARES se gerarem mais de um terço da sua receita bruta anual de jogo e atividades de jogo.

A Costa Rica, por sua vez, tem no turismo sua principal fonte de exportação. A imagem de país estável, seguro, que preserva a natureza, é que é "Pura Vida" (o lema dos costarriquenhos que se tornou uma forma de saudação e marca do país), joga a favor para atrair turistas endinheirados da Europa e dos EUA, principalmente. O impacto da pandemia tem sido forte na economia e no modo de vida local. Algumas ações foram tomadas para garantir que o setor turístico não fosse varrido do mapa no país. Por exemplo, pela Resolución n. DJUR-0069-04-2020-JM, de 23 de abril de 2020 (https://www.migracion.go.cr/Documentos\%20compartidos/Circulares\%20y\%20Directrices/2 020/COVID-19/D.JUR.\%200069-04-2020-JM.pdf) todos os turistas que entraram no país depois de 17 de dezembro de 2019 tiveram seus vistos automaticamente prorrogados até 17 de julho de 2020. O prazo legal foi prorrogado de 90 para 180 dias. O turista não precisa fazer nada. Essa ação possibilitou que turistas internacionais optassem por passar o período de quarentena no país, e seguissem seus trabalhos de forma remota. O resultado foi que isso chamou a atenção da mídia de seus países de origem, e eles foram objeto de matérias jornalísticas. As matérias, sempre em tom positivo para o país, tornaram-se ações de marketing gratuito para a Costa Rica. ("Costa Rica, la excepción de América durante la epidemia del coronavirus" - https://www.americaeconomia.com/politicasociedad/sociedad/costa-rica-la-excepcion-de-america-durante-la-epidemia-del-coronavirus; "Publicaciones internacionales resaltan a Costa Rica como destino turístico luego de la crisis por el coronavirus" - https://www.nacion.com/economia/politica-economica/publicacionesinternacionales-resaltan-a-costa/ELCW2V5HJVDUHFZBZMCALHTCMY/story/; "Família inglesa decidio extender sus vacaciones y pasar la cuarentena en Costa Rica" https://www.nacion.com/economia/negocios/familia-inglesa-decidio-extender-sus-

vacaciones-

y/N7AO2DVQJRD5RCS6HNKMPAHNVA/story/?li source=Ll\&li medium=bottom article\&li $\mathrm{pl}=\mathrm{c} 14 \mathrm{ee} 158-\mathrm{cb} 2 \mathrm{~b}-4532-9221-\mathrm{ffbf7f2e} 34 \mathrm{fc} \& \mathrm{li} \mathrm{tr}=\mathrm{bottom}$ article

Para a preservação do setor no país, o governo também tomou várias medidas que têm dois objetivos muito claros: "proteger o fluxo de caixa das empresas turísticas e dar apoio aos trabalhadores que ficaram sem sustento" (Carta aberta ao setor de turismo da Ministra do Turismo da Costa Rica, Maria Amalia Revelo Raventos, 25 de marco de 2020. Disponível em: $\quad$ https://www.ict.go.cr/es/documentos-institucionales/material-de-apoyocoronavirus/declaraciones-del-ict/1651-carta-abierta-al-sector-turismo/file.html).

Entre as medidas adotadas está a não cobrança de alguns impostos, a liberação de pagamentos de aluguéis, liberação de empréstimos com juros reduzidos e com pagamentos em 240 meses para vários setores, entre eles o turismo. Para os trabalhadores foi criado o "Plano Proteger" que possui um valor total de $3 \%$ do PIB do país e que visa oferecer uma 


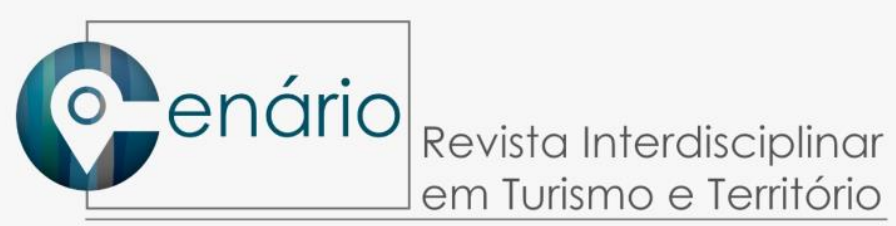

ajuda financeira aos que tiveram seus contratos de trabalho suspensos ou para os que tiveram sua renda reduzida. O resultado: várias publicações apresentam o país como um dos destinos mais promissores após a pandemia para as famílias passarem suas férias (https://www.larepublica.net/noticia/costa-rica-sera-el-destino-numero-uno-del-mundo-para-

surfear-pos-pandemia; https://en.travel2latam.com/nota/59987-costa-rica-o-pais-mais-bempreparado-para-a-pandemia-pos-covid-19; https://noticias.uol.com.br/ultimasnoticias/bbc/2020/05/01/coronavirus-qual-a-formula-da-costa-rica-pais-com-menor-numerode-mortes-por-covid-19-da-america-latina.htm).

Mas o país ainda precisa enfrentar outra forma de ameaça de surto da doença. Desde 2018 a crise política e social da Nicarágua, somada à repressão do governo daquele país, vem forçando muito nicaraguenses a saírem de seu país gerando uma onda migratória na América Central. A Costa Rica é um dos destinos escolhidos pelos nicaraguenses por ser fronteiriço e por sua qualidade de vida. De acordo com a ONU, pelo menos 23 mil tentaram obter asilo na Costa Rica apenas no primeiro semestre de 2018. Com o fechamento das fronteiras, devido à pandemia, os nicaraguenses arriscam suas vidas na travessia ilegal para a Costa Rica. Dois centros de acolhimento foram abertos na Costa Rica, um no Norte e outro no Sul do país, que tem capacidade de acolher dois mil refugiados. Criados com a ajuda da OIM (Organização Internacional para as Migrações) e da Agência de Refugiados das Nações Unidas, esses campos não parecem dar conta do fluxo migratório e o país terá que tomar outras providências.

Neste contexto, a contínua preocupação sobre a rápida aceleração do vírus realça que as ações na maioria dos países são um comprometimento com a vida, e as viagens só deverão voltar a acontecer quando existir total segurança atestada pelas autoridades mundiais de saúde. Contudo, o cenário desafia o setor turístico a pensar sobre o momento pós-Covid-19, e aponta dois caminhos: 1) mais ameaças se o setor continuar como está e 2) a necessidade de se repensar/reconstruir o setor.

O prejuízo econômico para os países que dependem do turismo é uma das ameaças. O Conselho Mundial de Viagens (WTCC) estima que esse prejuízo passe dos 2 trilhões de dólares em 2020 e que cerca de 75 milhões de pessoas percam seus postos de trabalho (ver: https://www.ambitur.pt/wttc-pandemia-da-covid-19-ameaca-ate-75-milhoesde-postos-de-trabalho-no-turismo/).

Este é um momento que requer uma desaceleração e um repensar do planejamento de viagens (turistas) e da inovação no setor. A tecnologia e a inovação podem ajudar o setor do turismo a superar essa crise. Alguns museus brasileiros estão oferecendo exposições virtuais, como o MASP (Museu de Arte de São Paulo) - que criou a \#maspemcasa, e o Inhotim em Minas Gerais. Museus espalhados pelo mundo vêm fazendo o mesmo, como o Reina Sofia, em Madrid, o Museu do Louvre, em Paris, e o Metropolitan, em Nova lorque. (ver: $\quad$ https://agenciabrasil.ebc.com.br/geral/noticia/2020-04/museus-promovem-visitasvirtuais-durante-pandemia)

É provável que o fluxo turístico doméstico seja o primeiro a ser retomado. As pessoas sentem-se mais seguras em viajar em seu país. Por suas dimensões continentais o Brasil pode e deve utilizar esse fato em seu benefício. Os gestores do turismo nacional podem elaborar pacotes nacionais e incentivar as viagens domésticas antes de incentivar as viagens internacionais. Desta forma, pequenos e médios empreendimentos do turismo podem se beneficiar facilitando a distribuição de renda oriunda do setor. De outro lado, o recebimento de turistas internacionais poderá ocorrer somente após as companhias aéreas retomarem a oferta das linhas internacionais que estão suspensas. Além disso, o país terá um árduo trabalho de marketing para fortalecer sua marca como um destino seguro, tanto no caso da doença em questão quando no caso da imagem negativa internacional gerada pela instabilidade política, econômica e social que estamos vivendo.

No âmbito global, é possível que o atual cenário influencie novos protocolos de viagem, como aconteceu após ataques de 11 de setembro de 2001. O Aeroporto Internacional de Puerto Rico (Aeroporto Luis Munõz Marín), por exemplo, instalou câmeras 


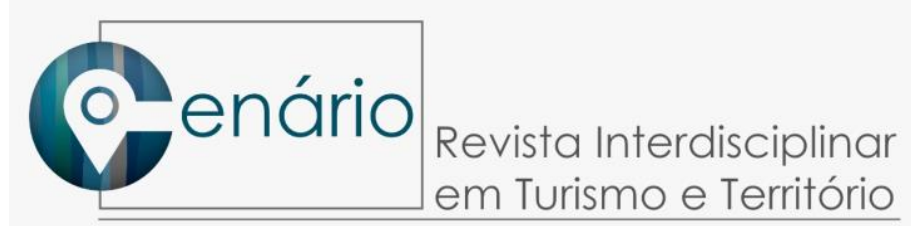

térmicas em suas instalações para medir os passageiros no check-in. As câmeras acionam um alarme caso alguém apresente temperatura igual ou maior a 38 graus Celsius. Muitos aeroportos terão que aumentar suas áreas para garantir uma distância segura entre os passageiros. Já os hotéis e restaurantes devem reforçar seus procedimentos de limpeza. (http://aracajumagazine.com.br/conteudo/economia-negocios/confira-as-possiveis-

mudancas-em-viagens-aereas-apos-a-

pandemia\#: :text=J\%C3\%A1\%20em\%20Porto\%20Rico\%2C\%20c\%C3\%A2meras,Mu\%C3 \%B10z\%20Mar\%C3\%ADn\%2C\%20em\%20San\%20Juan.).

Figura 2. Câmeras térmicas no Aeroporto de Puerto Rico.

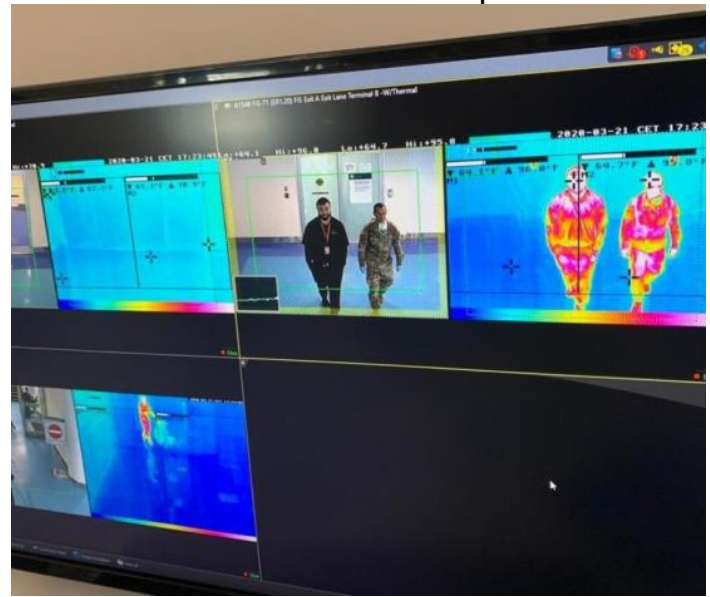

Fonte: Notícia publicada no site El nuevo dia (2020).

https://www.elnuevodia.com/negocios/empresas/nota/aeropuertoluismunozmarininstala11camaraspar atomadetemperatura-2554681/

Em torno da crise sanitária, tem se observado um enorme volume de informações. Número de doentes, mortos, evolução no país e comparativos com outros países, análises econômicas, políticas, sociais, relatórios de agências diversas, notícias nos jornais, e nas mídias sociais entre outros. Entre avalanches de pesquisas pela internet sendo desenvolvidas por meio de questionários longos e com perguntas dúbias, e um avalanche de lives no Instagram, Facebook, Google Meet, Zoom Meeting ou outras plataformas - todos com o tema do Covid-19 (desde a indústria da beleza, da comunicação, grupos minoritários, até da de calçados, hoteleira, gastronômica, e claro, da do setor de turismo e saúde), a pessoas chegam a ficar confusas e desorientadas. Esse fato ocasiona uma guerra de informação e desinformação e traz prejuízos a todos. Esse é o exemplo do medicamento hidroxicloroquina que foi inicialmente recomendado pelos presidentes dos EUA e do Brasil. Porém, após testes científicos que mostraram os perigos do remédio e a Organização Mundial da Saúde não indicar seu uso, o presidente dos EUA deixou de recomendá-lo, mas o presidente do Brasil não. Esse é apenas mais um episódio da desinformação e do radicalismo político existente em nosso país. Aliás, em 6 de junho de 2020 o site do Ministério da Saúde do Brasil saiu do ar por várias horas, e quando retornou omitia o histórico das mortes, dificultando 0 acesso transparente às informações. (https://noticias.uol.com.br/ultimas-noticias/rfi/2020/06/07/brasil-se-une-acoreia-do-norte-e-a-venezuela-ao-omitir-dados-da-covid-19.htm). Como poderão os turistas internacionais desejar visitar o Brasil num futuro próximo se a imagem do país se deteriora a cada dia no cenário internacional? E, sejamos francos, o atual Governo Federal Brasileiro em nada está agindo para ajudar a melhorar as condições internas, muito menos a imagem internacional do país. Não queremos ser pessimistas, mas é este o atual cenário que estamos enfrentando. 


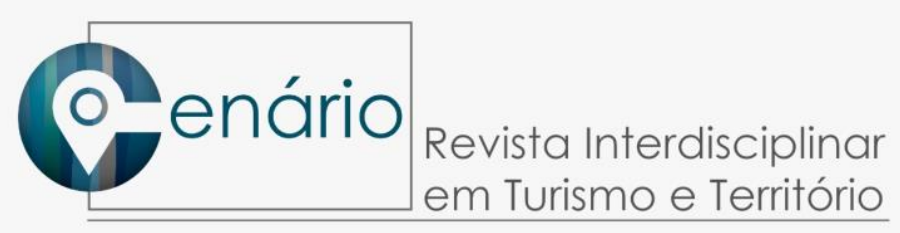

\section{CONSIDERAÇÕES FINAIS}

As reflexões que apresentamos neste artigo oferecem mais perguntas do que respostas ao momento vivido. Quanto tudo isso vai passar? Teremos uma vacina em pouco tempo? Queremos que a vida cotidiana volte a ser como era antes ou devemos agora implantar mudanças radicais? Estou/estamos disposto/s a mudar hábitos particulares em benefício da coletividade? O setor de turismo irá se recuperar economicamente no mesmo formato ou irá se reinventar? As pessoas terão segurança em viajar? O overtourism voltará a ser uma realidade? Estamos preparados para uma próxima pandemia? Quais ensinamentos podemos tirar deste momento histórico?

Outros autores também concordam que este momento nos apresenta muito mais perguntas do que respostas. Coelho e Mayer (2020, p. 3704), por exemplo, acrescentam outros temas que são importantes para o setor de turismo e merecem estudos futuros, tais como "os impactos emocionais e psicológicos da pandemia em viajantes, as restrições ao exercício de direitos fundamentais, a invasão de privacidade e a proteção de trabalhadores do turismo merecem a atenção de pesquisas futuras."

Algumas vozes se levantam para afirmar que não se trata de resgatar o turismo, mas sim de reconstruí-lo. Losada (2020), em artigo de opinião, afirmou que o "decrescimento turístico antes já era necessário, mas agora é uma prioridade absoluta" e que este é o momento para colocar o assunto em debate. "Sem esta transformação não haverá nem Green New Deal, nem Smart Cities, nem sustentabilidade, nem leite com migalhas de pão, e sim muitos pobres mais. Disto é consciente hoje em dia até o próprio setor turístico, que já fala em boca miúda de uma necessária revolução." (LOSADA, 2020). Nesta mesma linha está o pensamento de Niewiadomski (2020, p.4) afirmando que "os processos temporários de desglobalização estão dando ao setor do turismo global uma chance única de re-boot uma oportunidade irrepetível de se re-desenvolver de acordo com os princípios da sustentabilidade." Essa visão é endossada por C. Michael Hall, Daniel Scott \& Stefan Gössling (2020, p. 14) quando afirmam que "o futuro do turismo no planeta é baseado no impacto absoluto do turismo e dos turistas, e não nos efeitos relativos". Os autores complementam a reflexão expondo que "mesmo que exista uma maior eficiência no nível individual, não haverá um único aprimoramento na sustentabilidade global se o foco permanecer no crescimento" (p.14). Ou seja, o crescimento do turismo expresso em forma de números de viagens numa planilha ou num gráfico divulgado mensalmente pelas instituições oficiais, oculta uma realidade e não podem ser vistos como o todo do setor. Há muito além de tais números.

E nós, acadêmicos, o que podem fazer neste momento? Seguimos a orientação dada em relatório apresentada na lista TRINET, que é uma lista internacional de discussão formada por pesquisadores e profissionais de turismo. Segundo as contribuições de tais profissionais, à pergunta "O que podemos, como acadêmicos, fazer?", temos as seguintes respostas:

\footnotetext{
Ofereça seus serviços voluntariamente, pois o dinheiro é muito limitado. Trabalhe em colaboração com outras pessoas. Agora é a hora de colaborar. Forneça suporte de pesquisas direcionadas, inclusive para informar mudança de políticas. Compartilhe nossa pesquisa coletiva com os gestores públicos do turismo (municipais, estaduais e nacionais) e o setor de turismo. Promova uma maneira diferente de conduzir o turismo. (Relatório TRINET, 2 de abril de 2020).
}

Grandes surtos de doenças deixam marcas profundas em uma sociedade. Para além da ideia de "romantização", na qual a pandemia nos traz lições de vida (despertando atitudes de solidariedade, empatia e compaixão), ela também nos obriga a fazer esforços diários para nos mantermos saudáveis (do ponto de vista físico e mental), otimistas e com perspectivas positivas. As perdas de amigos e até mesmo parentes deixam cicatrizes 


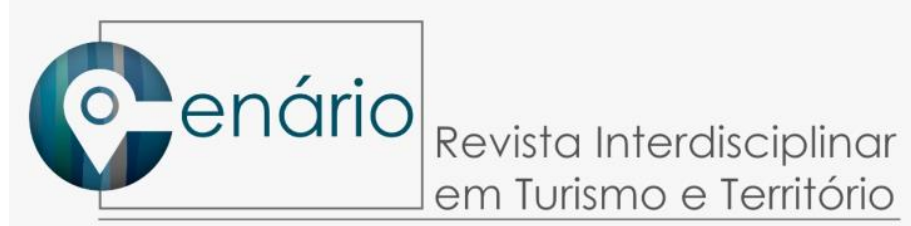

profundas em nós. São as vidas que importam. Que as pessoas vivam, e que vivam com qualidade. Em menor grau, o mau desempenho da economia mundial ou nacional, a depender de qual país estamos falando, também deixará marcas negativas, mexendo, inclusive, com o sonho das pessoas. As viagens são parte significativa desses sonhos. Impedidos de se deslocarem e sem dinheiro suficiente, muitos amantes do turismo e das viagens em geral, terão que aguardar pacientemente o fim dessa crise. É provável que demore ainda alguns meses ou até mesmo anos para a tal "normalidade" voltar. Mas, por tudo o que dissemos acima, ainda fica uma pergunta: queremos de voltar à normalidade?

\section{REFERÊNCIAS}

Alcalde, J.; Guitart, N.; Pitarchr, A. \& Vallvé, O. (2018). De la turismofobia a la convivencia turística: el caso de barcelona. In Revista de Investigación en Turismo ( $2^{\circ}$ ed., pp. 25-34). Barcelona, Espanha.

Ali, R. (2016). 'Exploring the Coming Perils of Overtourism'. Skift, 23-08-2016 [online]. Disponível em: www.skift.com (07-07-2018).

Beni, Mário Carlos. (2020). Saturação e Rejeição ao Turismo nas Destinações Turísticas. RBTUR. São Paulo (vol. 14, p. 1-8, maio/ago). http://dx.doi.org/10.7784/rbtur.v14i2.1847

Brasil. Ministério do Turismo. (2020). Coronavírus: informações para o setor de viagens/ medidas do governo federal [online]. Disponível em: http://www.turismo.gov.br/\%C3\%BAltimas-not\%C3\%ADcias/13422-cartilha-dominist\%C3\%A9rio-do-turismo-lista-a\%C3\%A7\%C3\%B5es-de-apoio-contracoronav\%C3\%ADrus.html. Acesso em 27 de maio de 2020.

Brasil. Ministério do Turismo. (2020). Manual sobre coronavírus [online]. Disponível em: http://www.turismo.gov.br/\%C3\%BAltimas-not\%C3\%ADcias/13428-mtur-apresenta-manualsobre-o-coronav\%C3\%ADrus-aos-viajantes-e-entidades-do-setor.html. Acesso em 27 de maio de 2020.

Brasil. Portaria no 255, de 22 de maio de 2020. Dispõe sobre a restrição excepcional e temporário de entrada no País de estrangeiros. Disponível em: http://www.in.gov.br/en/web/dou/-/portaria-n-255-de-22-de-maio-de-2020-25811413. Acesso em 27 de maio de 2020.

Brasil. Projeto de Lei $\mathbf{n} \mathbf{0} \mathbf{8 0 0}$, de 2020. Institui incentivos fiscais para o setor de turismo durante a pandemia de covid-19 (coronavírus), [online]. Disponível em: https://www25.senado.leg.br/web/atividade/materias/-/materia/141140. Acesso em 27 de maio de 2020.

British Broadcasting Corporation (BBC). (2020). Coronavirus: Jobs lost as hotel and tour firm collapses [online]. Disponível em: https://www.bbc.com/news/uk-scotland-scotlandbusiness-52663623. Acesso em 27 de maio de 2020.

Coelho, Mariana F.; Mayer, Veronica F. Gestão de serviços pós COVID-19: o que se pode aprender com o setor de turismo e viagens?. Revista Eletrônica Gestão \& Sociedade (14, n.39, p. 3698-3706 | Especial COVID-19 - 2020). Belo Horizonte, MG: Editora da FACEUFMG. 


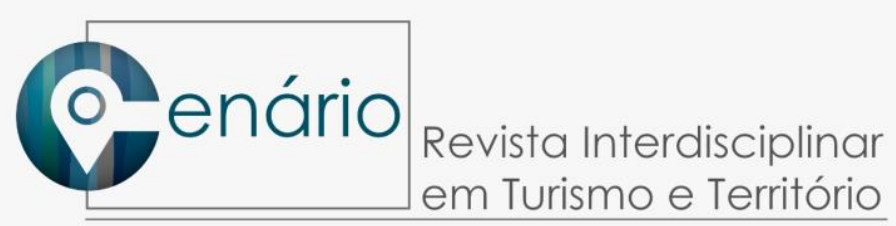

Hall, C. M.; Scott, D.; Gössling S. (2020): Pandemics, transformations and tourism: be careful what you wish for [online]. Tourism Geographies. https://go.euromonitor.com/whitepaper-consulting-2020-leveraging-market-research-for-

IPOs.html?utm campaign=SC 200423 IPO Market Resilience Index\&utm medium=Em ail\&utm source $=1$ Outbound\&mkt tok=eyJpljoiWkRKbVpXVTRaR0V3TXpOaylsInQiOilxNU d3NTQrK1BRWWhra00xb3F3VEw5MTFNUk9LdDI5QkEwQXINYmJNRWNuaEM5eE1maVZ FcnBuK2IxZHFiMDdCeFdOWVcyMnFLL0ZjdUd3Y1IYcHZjUWY5YjQyMzJ0ZzNtVIRzeTVxL2 JJUTRWVTNGcHpGZktpTIIJREp2a0tPayJ9. Acesso em 22 de maio de 2020.

Huete, R.; Mantecón, A. (2018). El auge de la turismofobia ¿hipótesis de investigación o ruido ideológico. Revista de Turismo y Patrimonio Cultural (vol. 16 - n.1, p.p. 9-19). Alicante, Espanha.

La Nacion (2020). Coronavirus: antes asfixiada por los turistas, Venecia ahora agoniza por su ausencia [online] Disponível em: /www.lanacion.com.ar/2363522. Acesso em 08 de jun. de 2020.

Losada, J. A. P. (2020). Por qué no hay que rescatar el turismo, y sí reconstruirlo. Diário de Sevilla [online]. Disponível em: https://www.diariodesevilla.es/opinion/tribuna/Juan-AntonioPavon-Losada-por-que-no-rescatar-turismo-reconstruirlo-Coronavirus-

Sevilla 0 1460254389.html. Acesso em 30 de abril de 2020.

Niewiadomski, P. (2020): COVID-19: from temporary de-globalisation to a rediscovery of tourism?. Tourism Geographies. DOI: https://doi.org/10.1080/14616688.2020.1757749

Panosso Netto, A.; Trigo, L. G. G. (2003). Cenários do turismo brasileiro. São Paulo, Aleph.

Pieri, V. S. G.; Panosso Netto, A. (2015). Turismo internacional: fluxos, destinos e integração regional. Coleção comunicação e políticas públicas (vol. 13). Boa Vista, RO: Editora da UFRR.

Portal Panrotas. (2020). 5 ideias do que pode mudar no Turismo pós-coronavírus [online]. Disponível em: https://www.panrotas.com.br/mercado/opiniao/2020/03/5-ideias-doque-pode-mudar-no-turismo-pos-coronavirus 172431.html. Acesso em 27 de maio de 2020.

Responsible Tourism (n.d.). Overtourism [online]. Disponível em: www.responsibletourismpartnership.org/overtourism. Acesso em: 08 de maio de 2010.

Revelo Raventos, M. A. (2020). Carta abierta al sector de turismo. Instituto Costarricense de Turismo - ICT. 25 de março de 2020 [online]. (Disponível em: https://www.ict.go.cr/es/documentos-institucionales/material-de-apoyocoronavirus/declaraciones-del-ict/1651-carta-abierta-al-sector-turismo/file.html).

The Globe and Mail. (2020). Coronavirus-fuelled tourism meltdown yields pros and cons for conservation [online]. Disponível em: https://www.theglobeandmail.com/life/travel/article-coronavirus-fuelled-tourism-meltdownyields-pros-and-cons-for/. Acesso em 27 de maio de 2020.

The New York Times. (2020). How Will Covid-19 Affect Future Travel Behavior? A Travel Crisis Expert Explains [online]. Disponível em: https://www.nytimes.com/2020/04/15/travel/q-and-a-coronavirus-travel.html. Acesso em: 27 de maio de 2020. 


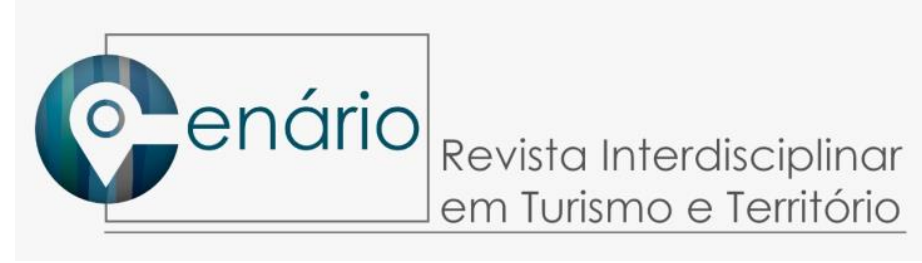

The Times. (2020). Could coronavirus push global tourism to the brink? [online]. Disponível em: https://www.thetimes.co.uk/article/could-coronavirus-push-global-tourism-tothe-brink-amsqwaj6l. Acesso em 27 de maio de 2020.

Viagem e Turismo (2020). O "novo normal" das viagens de lazer, segundo entidade mundial. Editora Abril [online]. Disponível em: https://viagemeturismo.abril.com.br/materias/o-novo-normal-para-a-volta-das-viagens-delazer-segundo-o-wttc/?utm source=whatsapp. Acesso em 01 de jun. de 2020.

World Tourism Organization (UNWTO). (2020). Impact Assessment of the COVID-19 Outbreak on International Tourism [online]. Disponível em: https://www.unwto.org/impactassessment-of-the-covid-19-outbreak-on-internationaltourism $>$. Acesso em 17 de maio de 2020.

World Tourism Organization (UNWTO), (2018). Centre of Expertise Leisure, Tourism \& Hospitality; NHTV Breda University of Applied Sciences; and NHL Stenden University of Applied Sciences. 'Overtourism'? - Understanding and Managing Urban Tourism Growth beyond Perceptions, Executive Summary, UNWTO, Madrid, DOI: https://doi.org/10.18111/9789284420070.

https://www.unwto.org/un-tourism-news-12

Zerva, K.; Palou, S.; Blasco, D.; \& Donaire, J. A. (2019). Tourism-philia versus tourismphobia: residents and destination management organization's publicly expressed tourism perceptions in Barcelona. Tourism Geographies (2ํe. vol. 21, p.p. $306-329)$. 